\title{
'My child, my choice': parents, doctors and the ethical standards for resolving their disagreement
}

\author{
DAVE ARCHARD*
}

Queen's University Belfast

\begin{abstract}
Disagreements between doctors and parents as to the appropriate treatment of a child have been exacerbated by a number of recent developments, especially the use of the internet. In normative terms there has been a popular assertion of a parent's right to choose the treatment of his or her child and this has been defended in the bioethics literature, often in the context of a preference for a harm over a best interests principle for adjudicating these differences. This article affirms the centrality of a best interest standard and criticises arguments for giving parental views a certain moral weight based upon the view that parents know best, or on the interests of the parents, or as consistent with the use of child protection principles, or in value uncertainty.
\end{abstract}

Keywords: best interests; harm; threshold; trigger; proprietarian; parental discretion; interests; value uncertainty.

\section{Introduction}

$\mathrm{R}$ ecent high-profile cases arising from unresolved disagreements between doctors and parents as to how the latter's children should medically be treated might suggest that conflict is now the norm in paediatric practice. These four cases - Ashya King, Charlie Gard, Isaiah Haastrup and Alfie Evans - are well-known and much discussed. ${ }^{1}$ The use of the courts to make a final determination of what should be done compounded the existing divisions between the parties. Any legal resolution of the issues is public and pits the disagreeing parties against one another in antagonistic fashion. Such judicial resolutions of the disagreement may well be final. Yet at the same, they may only serve to confirm an abiding sense of tragic loss, deep frustration at the outcome and an irretrievable, rancorous breakdown of relations between the litigating parties.

* School of History, Anthropology, Philosophy and Politics; d.archard@qub.ac.uk.

1 Portsmouth City Councilv (1) Nagmeh King (2) Brett King (3) Southampton Hospital Trust (4) Ashya King (by his Children's Guardian) [2014] EWHC 2964 (Fam); Great Ormond Street Hospital v (1) Constance Yates (2) Chris Gard (3) Charles Gard (a Child by his Guardian Ad Litem) [2017] EWHC 972 (Fam); King's College Hospital NHS Foundation Trust v (1) Takesha Thomas (2) Laure Haastrup; (3) Isaiah Haastrup [2018] EWHC 127 (Fam); Alder Hey Children's NHS Foundation Trust v (1) Thomas Evans (2) Kate James (3) Alfie Evans (a Child by bis Guardian) [2018] EWHC 308 (Fam). 
Nevertheless, it is important to add the following. First, partnership in decisionmaking is not an impossible ideal. Such evidence as there is suggests that discussions between parents and doctors as to the best treatment of a child, even in end-of-life cases, need not result in conflict. A study of the Rapid Response work of the Clinical Ethics Service at Great Ormond Street Hospital showed that of 203 cases in which doctors recommended the withdrawal of treatment from children in intensive care, 186 cases yielded agreement after discussion with the parents, and further discussions produced resolution in six of the remaining $17 .^{2}$

Second, at the same time, a combination of factors has encouraged parents to challenge the views of doctors and to pursue alternative forms of treatment. Most obviously, access to the internet and to social media have given parents the means to research and share with other parents treatment options, to crowd-fund such treatments as might be thereby disclosed, and to publicise both their disagreement with doctors and their own preferred options of care. ${ }^{3}$

These factors merit further extended discussion. However, what will be considered here is the emergence of a view - one that these factors undoubtedly gave particular emphasis to - that parents should be permitted to make the final decision as to what care is appropriate for their child. The supposed corollary of that view - that doctors should make such decisions - is then regarded as an illicit detention of the child by health professionals against the will of the child's parents. These two views found popular expression in slogans on posters or in public statements by support groups at the time of the Charlie Gard case. 'My child, my choice'4 was one such slogan, and a spokesperson for Charlie Gard's parents said of the court's decision, in that case to cease treatment, that it was tantamount to Charlie being 'taken prisoner by the NHS and by the state'. 5

These views can be contrasted with the view which holds that, where there is disagreement between doctors and parents, what ought medically to be done for any child is what is in the child's best interests. Indeed, that should be the sole decisive consideration. What is determined to be in a child's best interests may be what the parents want, but it need not be. Crucially, what is important is what is best for the child, not what either doctors or parents want.

In what follows I want to defend this view against the emergent view of parental rights of choice. I will do so by casting doubt on such reasons as have been given for thinking parents should be free to choose their child's medical care and by making clear why it is important to see best interests as the appropriate standard for medical decisionmaking in the context of disagreement. I shall regard the most plausible alternative

2 Joe Brierley, Jim Linthicum and Andy Petros, 'Should Religious Beliefs be Allowed to Stonewall a Secular Approach to Withdrawing and Withholding Treatment in Children?' (2013) 39(9) Journal of Medical Ethics 573-7.

3 Tessa Richards, 'When Doctors and Patients Disagree' (2014) British Medical Journal 349-50; Brynn K Wainstein et al, 'Use of the Internet by Parents of Paediatric Patients' (2006) 42 Journal of Paediatric Child Health 528-32; Neera Bhatia, 'Three Ways the Charlie Gard Case Could Affect Future End-of-life Cases Globally' (The Conversation, 25 July 2018) < https://theconversation.com/three-ways-the-charlie-gard-casecould-affect-future-end-of-life-cases-globally-81168>. See also, Bernadette Richards, 'Social Media: The Unnamed Plaintiff' (2018) Journal of Bioethical Inquiry (2018) <www.semanticscholar.org/paper/SocialMedia\%3A-The-Unnamed-Plaintiff.-Richards/572b1b5649d65c22738242c47250515880da4ca6>.

4 'Reality Check: Why Don't Charlie Gard's Parents Have the Final Say? ' (BBC News, 14 July 2017) <www.bbc.co.uk/news/uk-40600932>.

5 'Gard Spokesperson: Baby Charlie is Effectively “a Prisoner of the State”" (Sky News, 16 July 2017) $<$ https://news.sky.com/story/gard-spokesperson-baby-charlie-is-effectively-a-prisoner-of-the-state$10949732>$. 
standard to best interests as that which permits parents to make decisions for their children so long as they do not, in making such choices, cause or seriously risk causing significant harm to the child. In the interests of simple expression, I shall thus contrast a 'best interests' and a 'harm' standard or principle.

Crucially, what follows is not an essay in the legal interpretation of the relevant cases. It is not about whether the judgments in these are correctly argued. Rather it is an exercise of normative jurisprudence. It asks the question: what moral - rather than juristic reason might there be for thinking that parents do have the right to make medical decisions for their children, or that something other than the interests of the child is the appropriate way to resolve disagreements between doctors and parents? Reference will be made to legal cases, but in order to illustrate what is here argued to be of normative relevance and importance. If judges are cited it is not to the end of showing their legal judgment to be the right one, but rather as providing good expressions of the underlying principle that is defended here. The conclusion of this essay is that best interests should continue to be what it is stated, in the words of Baroness Hale cited below, to be, namely the law's 'gold standard' for adjudicating disagreements between parents and doctors.

In this spirit let me cite at the outset some clear legal statements of the centrality of the best interests standard. In the Charlie Gard case at appeal McFarlane LJ stated:

As the authorities to which I have already made reference underline again and again, the sole principle is that the best interests of the child must prevail and that must apply even to cases where parents, for the best of motives, hold on to some alternative view. ${ }^{6}$

In the case of Alfie Evans the appeal judges stated that the decision as to what treatment Alfie should receive 'must be governed by an objective assessment by the court of what is in the child's best interests'. ${ }^{7}$ They cited Baroness Hale's view in the Supreme Court that in such cases the best interest principle is the 'gold standard' by which decisions as to what shall be done for a child medically must be adjudicated. ${ }^{8}$ What follows now is an ethical vindication of the claim that the best interests standard is indeed gilded.

\section{The liberal family and parental rights}

I start with a simple-minded, and simplified, model of the role of parents in the care of children, one that operates within what can be broadly characterised as liberal democratic societies. ${ }^{9}$ This is that children fare best if their upbringing is entrusted in the first instance to some adults who discharge a duty of care. It is further thought that this duty is discharged by the provision of certain goods (such as a safe and secure environment in which the child might develop) and by the exercise of parental choices - as to such matters as food, play, television viewing, bedtime reading and culture - to the exclusion of others and in private. It is for the parents to make these choices and for them to do so in the absence of supervision and monitoring of their parental activities.

6 Great Ormond Street Hospital for Children NHS Foundation Trust v Yates [2017] EWCA Civ 410, per McFarlane LJ, para 112.

7 Alder Hey Children's NHS Foundation Trust v Evans [2018] EWCA Civ 805, per Davis, King, and Moylan LJJ, para 67.

$8 \quad$ Ibid para 34.

9 David Archard, The Family: A Liberal Defence (Palgrave Macmillan 2010). 
Within contemporary English-speaking moral and political philosophy this liberal model is generally endorsed. ${ }^{10}$ It is essentially a model of the family minimally understood as an institution in which some adults ${ }^{11}$ undertake responsibility for the care and upbringing of a particular child or children. Nevertheless, the family thus understood can take a number of different familial forms. ${ }^{12}$

The liberal model is thus neutral on questions of how many adults may be parents, on the question of the gender and marital status of the parent, and on their genetic relation to the children. It is consistent with different accounts of how adults get to be parents of any particular child. It can be defended in terms of the value to individuals of acting as parents, ${ }^{13}$ or by the thought that alternatives to the family - such as collective-rearing institutions - are appallingly bad. ${ }^{14}$

The important point to make is that no one who endorses the liberal model believes that parents are free to make any choice for the child in their care. Some indeed believe that parents should be constrained so as not to impose on their child any particular life view, such as a set of religious beliefs. They should not 'enrol' children into any such view, ${ }^{15}$ or must ensure that children have an 'open future'. ${ }^{16}$ But at a minimum parents are not entitled to act contrary to the interests of those in their care.

For instance, it is perfectly possible to view adults as deriving value from being parents whilst insisting that the terms of permissible parenting are given in the first instance by what serves the interests of children. Thus, Brighouse and Swift, who defend this view of why parents should be allowed to make decisions for their children, are clear that parents are to be viewed as trustee or fiduciary rights-holders, possessing and exercising such parental rights as they do because these rights are instrumental to the well-being of those for whom they act as trustees, in this instance children: 'Parents' rights over their children - what others have a duty to let them do to, with, or for those children - are justified, at root, by the children's interests, not those of their parents'. ${ }^{17}$

This is important. Allowing that people should be parents where this means making choices - in private and free of interference from others - of how children within their care are brought up does not amount to the grant to parents of a general permission to make any choice in respect of those children's care. It is an entrusting to adults of a right or permission to make choices for children that is justified in the last analysis by the welfare or interests of those children.

10 Harry Brighouse and Adam Swift, Family Values: The Ethics of Parent-Child Relationships (Princeton University Press 2014); John Bigelow, John Campbell, Susan M Dodds, Robert Pargetter, Elizabeth W Prior and Robert Young, 'Parental Autonomy' (1988) 5(2) Journal of Applied Philosophy 183-96; Ferdinand Schoeman, 'Rights of Children, Rights of Parents, and the Moral Basis of the Family' (1980) 91 Ethics 6-19; David Archard, Children, Rights and Childhood (3rd edn, Routledge 2015) Part III 'Children, Parents, Family and State'.

11 'Adults' is understood as including the possibility of a single adult.

12 David Archard, 'Family and Family Law: Concepts and Norms' in Elizabeth Brake and Lucinda Ferguson (eds), Philosophical Foundations of Children's and Family Law (Oxford University Press 2018) 59-72.

13 Brighouse and Swift (n 10).

14 Veronique Munoz-Dardé , 'Is the Family then to be Abolished?' (1999) XCIX Proceedings of the Aristotelian Society $37-56$.

15 Matthew Clayton, Justice and Legitimacy in Upbringing (Oxford University Press 2006).

16 Joel Feinberg, 'On the Child's Right to an Open Future' in William Aiken and Hugh LaFollette (eds), Whose Child? (Rowman \& Littlefield 1980) 124-53.

17 Brighouse and Swift (n 10) 54. 
Thus, on the liberal model of the family, the standard view of the limits of parenting is that a parent who occasions or risks causing serious harm to a child in his or her care should be subject to officially sanctioned measures. These can run from regular or ongoing monitoring, through the temporary removal of children from their care, to the re-allocation of parental responsibilities to other adults. This is both the justification of and the specification of the form taken by child protection within a liberal society. The state acts as parens patriae, entrusted with the safeguarding in the final analysis of the interests of the weakest members of its citizenry. 18

Significantly, child protection on this model is normally action taken after the children have been initially allocated to their parents. It thus falls short of ex ante parental licensing defended by some philosophers ${ }^{19}$ that would deny anyone deemed to risk seriously harming a child in their care the opportunity to be a parent.

Even the USA, which is seen as constitutionally enshrining a principle of parental libertarianism, does not endorse unconstrained parental choice. It is true that US Supreme Court judgments have expressed the ideal of parental rights and the sanctity of the family. A classic example is Meyer $v$ Nebraska (1923), which concerned a prohibition on the teaching of a foreign language by a parent to his child. The court held that such a prohibition violated the Fourteenth Amendment to the Constitution that affirms: 'No State shall . . . deprive any person of life, liberty, or property, without due process of law.' The court took that liberty to denote:

... not merely freedom from bodily restraint but also the right of the individual to contract, to engage in any of the common occupations of life, to acquire useful knowledge, to marry, establish a home and bring up children, to worship God according to the dictates of his own conscience and generally to enjoy those privileges long recognized at common law as essential to the orderly pursuit of happiness by free men. ${ }^{20}$

It thus set the liberty of parenting on all fours with freedom of conscience and religion.

Yet, US Supreme Court judgments have also emphasised what parents cannot do. They have done so inasmuch as they recognise that the liberty of adults to make life choices that are self-harming does not encompass a freedom to make choices that are harming of those in their care.

There is thus a classic judgment to be found in Prince v Massacbusetts [1944]. The case arose from the actions of a Jehovah's Witness, Sarah Prince, who took a nine-year-old girl under her care onto the streets to distribute religious literature in exchange for voluntary contributions. She thereby violated child labour laws, and the Supreme Court in upholding her conviction clearly affirmed that parental authority over a child is not absolute and can be restricted if the parent, or guardian, is acting against the child's

18 Classic statements of the liberal standard of child protection include: Richard Bourne and Eli H Newberger, "Family Autonomy" or "Coercive Intervention"? Ambiguity and Conflict in the Proposed Standards for Child Abuse and Neglect' (1977) 57 Boston University Law Review 670-706; M D A Freeman, 'Freedom and the Welfare State: Child-Rearing, Parental Autonomy and State Intervention’ (1983) Journal of Social Welfare Law 70 -91; Michael Wald, 'State Intervention on Behalf of "Neglected" Children: A Search for Realistic Standards' (1975) 27(4) Stanford Law Review 985-1040. A classic account of how the liberal standard works in practice is Robert Dingwall, Joen Eekelaar and Topsy Murray, The Protection of Children: State Intervention and Family Life (2nd edn, Quid Pro 2014).

19 Hugh LaFollette, 'Licensing Parents' (1980) 9 Philosophy and Public Affairs 182-97 and 'Licensing Parents Re-visited' (2010) 27(4) Journal of Applied Philosophy 327-43; Andrew J Cohen, 'The Harm Principle and Parental Licensing' (2017) 43(4) Social Theory and Practice 825-49.

20262 US [1923] 390, 399; emphasis added. 
interests. The judges memorably stated: 'Parents may be free to become martyrs themselves. But it does not follow that they are free in identical circumstances to make martyrs of their children before they have reached the age of full and legal discretion when they can make that decision for themselves. ${ }^{21}$

The slogan 'My child, my choice' is thus attractively simple, but it is also evidently and deeply mistaken. Interestingly, it may echo a familiar maxim employed by pro-choice feminists, 'My body, my choice'. This was intended to give expression to the idea that woman have reproductive autonomy and may justifiably decide to terminate a pregnancy. However, most philosophical accounts of personal autonomy do not speak about the body, ${ }^{22}$ and the idea of personal autonomy seems distinguishable from that of bodily ownership. ${ }^{23}$ Moreover, those opposed to abortion can easily respond that any putative rights to ownership of one's own body are constrained by the rights of others, in this case that of the unborn child within a woman's body. Parents do not have rights over their children as they do over their own bodies. Moreover, parents do not own their children. This is so even if the 'proprietarian' view of parents as owners of their offspring can be found in Roman law ${ }^{24}$ and has found some favour with a few philosophers. ${ }^{25}$ Yet, the emergence of a recognition that children are independent persons with rights has been correlate with a decline in parental rights. ${ }^{26}$ In sum, a parent cannot choose for a child simply because that child is the parent's. 'This is my own child' does not mean, nor does it imply 'This is a child that I own.'

\section{The harm principle and best interests}

The foregoing sketch of the liberal model of the family in which the harm standard is the basis of the limits of permissible parenting might suggest the following. That standard should be the means of adjudicating disagreements between doctors and parents. In other words if parents lose their right to parent only if they cause or risk serious harm to their children, then their decisions as to the treatment their child receives should be respected so long as these do not infringe the harm principle.

To show that this implication is mistaken and to defend the view that it is a best interest principle that should operate to adjudicate medical disagreements, I will argue the following. First, I distinguish how and why the harm standard differs from the best interest standard. Second, I critically evaluate the reasons that have been given for favouring the harm standard over the best interest standard in cases of disagreement.

The harm principle is a threshold trigger principle that licenses legal intervention into the lives of citizens. Its canonical expression in respect of adults is to be found in John Stuart Mill's On Liberty where it is stated that the state may only interfere with the actions

21321 US [1944] 158, 170.

22 Sarah Buss and Andrea Westlund, 'Personal Autonomy' The Stanford Encyclopedia of Philosophy, Edward N Zalta (ed) (Spring 2018 edn, Stanford University) <https://plato.stanford.edu/archives/spr2018/entries/personalautonomy $>$.

23 David Archard, 'Informed Consent: Autonomy and Self-ownership' (2008) 25(1) Journal of Applied Philosophy 19-34.

24 W L Lacey, 'Patria Potestas' in B Rawson (ed), The Family in Ancient Roma: New Perspectives (Croom Helm 1986) $120-44$.

25 Jan Narveson, The Libertarian Idea (Temple University Press 1998) 272-4; Edgar Page, 'Parental Rights' (1984) 1(2) Journal of Applied Philosophy 187-203; B Hall, 'The Origin of Parental Rights' (1999) 13(1) Public Affairs Quarterly 73-8.

26 John Eekelaar, 'What are Parental Rights?' (1973) 89 Law Quarterly Review 210-34; Susan Maidment, 'The Fragmentation of Parental Rights' (1981) 40(1) Cambridge Law Journal 135-58. 
of individuals 'to prevent harm to others' ${ }^{27}$ Mill was clear, as others have been subsequently, that children need to be protected against the injurious actions of others as well, unlike adults, as their own actions.

Thus, the harm principle specifies a level of parental care, the falling below of which sets into operation measures of child protection. When, but only when, parents cause or risk causing serious harm to their children, can state agencies intervene into the family and take appropriate measures to protect the child from further actual or risked harm. What measures are subsequently judged appropriate may then be determined by a best interests principle. The best interests principle is not then, as Douglas Diekema understands it, a 'threshold principle for intervention' in the same way as a harm principle. $^{28}$

The best interests principle and a harm principle do not conflict or offer themselves as alternative standards, since they are used to make essentially different decisions: whether there shall be intervention into the life of a family to protect a child and how, afterwards and in the wake of that intervention, the child shall be cared for.

It should be added that the temporal language used in the making of the distinction should not suggest that there is a simple chronological order by which an initial intervention is then succeeded by a disposal of the child. One and the same intervention could be triggered by an occasioning of harm and be directed to the promotion of the harmed child's best interests.

This important distinction in the way that the two standards function can be justified as follows. We should not hold parents in their quotidian care of any child to a duty of providing only such care that is in the best interests of a child. Parents must provide a reasonable level of care. They are not required always and only to do what maximises the welfare of any child in their care. They need not be held liable for not choosing the best education, best leisure activities, food, and so on. Such a requirement would be unreasonably and unfeasibly demanding. At the very least, it would involve parents selfsacrificially failing to consider their own interests. ${ }^{29}$

However, no one who outlines and defends what has been termed the liberal model of parenthood and the associated liberal standard of justified intervention into family life believes that parents are required to do what is best for their children; indeed, they may do considerably less. Yet, when they do significantly harm their children (or risk doing so), then, but only then, may the state and its agencies interfere to protect the child. Bearing in mind the statement made at the outset that judges are cited not to the end of showing their legal judgment to be correct, but rather as providing good expressions of underlying principles, the following is a wonderfully clear and eloquent statement of the view defended here. Hedley J, who, in turn, had quoted Lord Templeman's view that, 'It matters not whether the parent is wise or foolish, rich or poor, educated or illiterate, provided the child's moral and physical health are not in danger', ${ }^{30}$ comments:

27 John Stuart Mill, On Liberty, Gertrude Himmelfarb (ed with introduction) (Penguin 1974 [1859]) 'Introductory'.

28 Douglas Diekema, 'Parental Refusals of Medical Treatment: The Harm Principle as Threshold for State Intervention' (2004) 25 Theoretical Medicine 243-64.

29 E Salter, 'Deciding for the Child: A Comprehensive Analysis of the Best Interest Standard' (2012) 33 Theoretical Medicine and Bioethics 179-98.

30 Re KD (a Minor Ward) (Termination of Access) 1 AC 806, [1988] 2 FLR 139, 812 and 141. 
There are those who may regard that last sentence as controversial but undoubtedly it represents the present state of the law in determining the starting point. It follows inexorably from that, that society must be willing to tolerate very diverse standards of parenting, including the eccentric, the barely adequate and the inconsistent. It follows too that children will inevitably have both very different experiences of parenting and very unequal consequences flowing from it. It means that some children will experience disadvantage and harm, while others flourish in atmospheres of loving security and emotional stability. These are the consequences of our fallible humanity and it is not the provenance of the state to spare children all the consequences of defective parenting. In any event, it simply could not be done. ${ }^{31}$

Yet, Hedley $\mathrm{J}$ is also explicit that the law should intervene when it is satisfied that the child is subject to or at risk of significant harm.

The general basic point is worth re-emphasising. The law should acknowledge that it is on the whole and on balance best that parents should rear children, whilst also accepting that parents will differ greatly in their abilities to do so. Most if not all will fail to do what is best for their child. Yet, the state may only intervene into family life to protect a child when parental standards of care fall below a threshold of significant harm.

The crucial difference between a harm and a best interests standard should be spelled out. To harm another, on a familiar and generally endorsed view within moral philosophy, is to 'set back' a person's interests from what they would otherwise be or should be in the normal course of events. ${ }^{32}$ It is essentially to make someone worse off. By contrast, to act in another's best interests is to promote those interests to the greatest degree possible. It is essentially to ensure that someone is as well off as they can be.

There may yet be a gap between not harming a child and doing enough or providing a reasonable level of care. Thus, Jeffrey Blustein defends a 'satisficing parentalism' as opposed to the maximising version required of a best interests principle strictly construed. ${ }^{33}$ Nevertheless, doing enough or what is reasonable or as much as one can may still be more than simply avoiding harm. This means that we may only intervene to protect a child if a parent harms that child (or risks doing so), yet hold parents to a moral duty to do more than simply not harm their offspring. It would be a further question as to what measures, short of intervention, might be appropriate to ensure that parents discharge that duty.

This distinction between the scope and functional role of a best interests and a harm principle is clear. Various writers do recognise the difference. Loretta Kopelman, for instance, argues that the best interests standard may be used in at least three different ways, one of which is as a threshold principle for intervention into family life. ${ }^{34}$ In fact, as she acknowledges, whilst the standard may then be used as a means of determining what shall subsequently be done, it is the occasioning of harm that in standard child protection procedures in fact triggers intervention. Again, Charles Foster sees the harm

31 Re L (Care: Threshold Criteria) [2007] 1 FLR 2050.

32 Joel Feinberg, Harm to Others, vol 1 of The Moral Limits of the Criminal Law (Oxford University Press 1984).

33 Jeffrey Blustein, 'Doing the Best for One’s Child: Satisficing Versus Optimizing Parentalism’ (2012) 33 Theoretical Medicine and Bioethics 199-205.

34 Loretta Kopelman, 'The Best Interests Standard as Threshold, Ideal and Standard of Reasonableness' (1997) 22 Journal of Medicine and Philosophy 271-89. 
principle as useful for 'triage' in the sense of that term as used in medical emergencies, namely as determining where resources are best devoted, namely to the most urgent cases. In the case of child protection, the principle of triage means attending first to those children suffering or at risk of serious harm. ${ }^{35}$

Others writing in this area simply fail to see this essential difference between the contexts in which the harm and best interest principles operate. They are thus disposed to see them as competing alternative standards for evaluating the choices to be made of how children should be treated medically. In adjudicating that competition, there is then much discussion of whether the charge of indeterminacy applies equally to both principles or more obviously, and fatally, to that of best interests. Giles Birchley, for instance, sees it as important, in defending the best interests principle against the harm principle as a standard of medical decision-making, to respond to the charge often made that best interests but not harm is vulnerable to indeterminacy. ${ }^{36}$

This is all beside the point if the two standards do not in fact offer themselves as principled means of answering the same question. Equally beside the point, and for all the same reasons, is any attempt to favour one principle over the other by demonstrating that its full normative specification, but not that of the other, cannot be made given the existence of deep-lying moral disagreements or the fact of moral pluralism. Here, the thought is that what can be understood by 'best interests' but not, by contrast, what is meant by 'harm' broaches significant and ultimately irresolvable moral disputes.

There is also no point in arguing that using a harm principle to resolve medical agreement is to be preferred to a best interests principle because such use is consistent with the employment of the harm principle in child protection. ${ }^{37}$ There is no point, to labour the basic truth, because the harm principle functions in the latter context, that of child protection, as a trigger for intervention into the family. 'Best interests' is then employed as the standard for determining what shall be done once the need for child protection has been triggered.

\section{The context of medical disagreement}

However, the context within which medical disagreement must be adjudicated is not analogous to that in which child protection - the initial intervention into the life of a family - is triggered. In the first place, there is a difference between a case in which parents have failed to bring their sick child to the attention of doctors and that in which they have done so but have come to disagree about what treatment is appropriate. The first kind of case is arguably one in which the parents are guilty of neglect or abuse and thus in which child protection measures may be appropriate. ${ }^{38}$ Three of the four cases cited at the outset are of the second kind, inasmuch as disagreement about treatment can include one about whether or not life-preserving treatment should be continued.

The fourth, that of Ashya King, was one in which a disagreement about treatment led the parents to remove him from the care of the treating hospital and to seek treatment

35 Charles Foster 'Harm: As Indeterminate as "Best Interests", but Useful for Triage' (2016) 42 Journal of Medical Ethics 121-2.

36 Giles Birchley, 'Harm is All You Need? Best Interests and Disputes about Parental Decision-making' (2016) 42 (2) Journal of Medical Ethics 111-15.

37 D Wilkinson and M Nair, 'Harm isn't All You Need: Parental Discretion and Medical Decisions for a Child' (2016) 42(2) Journal of Medical Ethics 116-18.

38 Kathleen Knepper, 'Withholding Medical Treatment from Infants: When is It Child Neglect' (1994-1995) 33 University of. Louisville Journal of Family Law 1-53. 
abroad. On the liberal child protection model such an action could be viewed as equivalent to a failure to treat and thus as meriting child protection measures. To be clear, the merits or otherwise of the legal judgment in that case are not being considered here. Rather, it is important to recognise the critical distinction between harming a child by failing to make treatment possible and acting in the best interests of a child by choosing the best possible treatment.

Second, parents who bring their child to the attention of and care by doctors need not be thought on the liberal model of parenthood as surrendering all their rights to act in the first instance as their child's guardians. Indeed, parents can act as proxy choosers for their children by giving consent to proposed treatment options. Nevertheless, it is important to acknowledge that a proxy decision-maker is morally obligated to make those decisions on behalf of another that accord with the other's known wishes or, as would be the case with an infant who cannot be thought of as having made known any wishes, what is in the other's best interests. ${ }^{39}$

Third, if and when any final determination of what treatment the child should receive has been made that goes against the parents' wishes, such a determination differs from how the liberal model of parenthood understands an intervention into the family to protect a child against serious harm. No general suspension of the rights of the parents is involved. No judgment need be made as to the causing by the parents of harm to their children. It is not the case that others - foster or adoptive parents, temporary guardians or carers - now do what the parents would otherwise do. Rather, doctors provide treatment for a child whose parents remain its primary guardians. Finally, the decision to overrule the parents' wishes is in a limited and specific domain, namely medical treatment of the child for such time as the child needs medical care.

In sum, the harm principle is relevant in the context of medical treatment in requiring that a sick child should be treated and in ruling out those initial interventions and treatments that occasion harm. Should it then be used when there is disagreement between doctors and parents as to what that treatment should be? The argument here is that the best interests principle alone should determine what is done. To think otherwise - and to represent the harm principle as the only basis on which parental views as to treatment should be overruled - is, once again, to confuse the threshold function of the harm principle with the standard of appropriate care.

If the choice is between the conflicting preferences of doctors and parents, it is unclear why one should not adjudicate by means of a best interests principle.

In front of us lies a sick child. Why is it not obvious that we should do the best we can for that child? It seems patently odd to say simply that we should do whatever does not harm the child. Consider how the liberal model of child protection understands what the state should do. A child is removed from the care of her parents because in that care she is being harmed or exposed to the significant risk of harm. What shall we now do? We should surely make arrangements for that subsequent care of the child that promotes her best interests, whether, for example, this is with adoptive parents, one of the original parents, or with members of the extended family. How would a harm principle help with a decision as to her future care? One obvious reason it may not help is that, whilst it will rule out some future care arrangements (for instance, by a parent who has proved to be

39 Tom L Beauchamp and James F Childress, Principles of Biomedical Ethics (5th edn, Oxford University Press 2001) 99-103; Allen E Buchanan and Dan W Brock, Deciding for Others: The Ethics of Surrogate Decision-making (Cambridge University Press 1990) 93-126. 
abusive or neglectful), it will not of itself serve to adjudicate between others (adoptive parents or other family members, for example). But what will help is a best interests principle. What is the best available care that can be provided for this child who cannot continue safely to be cared for as before by her original guardians?

Now of course the analogy of child protection is here of limited use. We are speaking of the making of permanent arrangements for the subsequent upbringing of a child. In the medical context we are talking about time- and scope-limited care. Moreover, and most importantly, the disagreement between doctors and parents may not be resolvable by appeal to the harm principle, as it would be if the abusive parents in a child protection case wished to continue caring for their child. Indeed, we need carefully to spell out the features of the kind of case of medical disagreement that causes problems. Two are crucial.

First, it is a case in which the child is incapable of expressing a view as to the treatment he or she wishes. Article 12 of the UN Convention on the Rights of the Child states that:

States Parties shall assure to the child who is capable of forming his or her own views the right to express those views freely in all matters affecting the child, the views of the child being given due weight in accordance with the age and maturity of the child. ${ }^{40}$

The cases that have provoked most heated debate and discussion have been those of severely ill babies. These are not children capable of forming their own views.

Equally, these are children who fall well below the required threshold of 'Gillick competence'. This is the capacity - of understanding and intelligence - that legal minors may demonstrate in respect of some matter affecting their interests such that 'parental right yields to the child's right to make his own decisions'. ${ }^{41}$ The fact that the child does not have a voice that should be taken into account means that the disagreement that needs to be resolved is a simple one between doctors and parents. I assume that the parents speak with one voice, an assumption that I make for the purposes of further argument, but not without acknowledging that in at least some cases parents may disagree.

Second, the disagreement in question as to what is best for the child is allowed to be a reasonable one and not one that can be adjudicated simply by dismissing the preferences or views of either party as harmful for the child or as unreasonable. That is to say that both parties have good reasons for their views and that those views do not run afoul of the harm principle. Of course, what a parent wants might cause the child harm or risk doing so. However - as was made clear earlier - there is a difference between harming and not maximally promoting the interests of another. So, if we do have such a disagreement, why should we give a particular weight or importance to the parents' views?

\section{Giving weight to parental views}

Against the view defended here that in such cases of disagreement there should be a determination of what is best for the child is a claim that the parents' views should be favoured over the doctors'. I will outline the most interesting version of the claim and then consider various arguments as to why the views of parents should outweigh those of doctors. These - in sum - are that parents know best what is best for their children, that their interests should be taken into account, and that we are deciding within a context of value pluralism.

40 UN Convention on the Rights of the Child 1989 <www.ohchr.org/en/professionalinterest/pages/crc.aspx>.

41 Gillick $v$ West Norfolk Health Authority [1986] 1 AC 112, 186 (Lord Scarman). 
One influential, thoughtful and intelligently designed proposal in the case of disagreement between parents and doctors is captured by the idea of a zone of parental discretion. ${ }^{42}$ The zone in question is the ethically protected space where parents may legitimately make decisions for their children, even if their decisions are sub-optimal for those children (i.e. not absolutely the best for them)'. They may be sub-optimal, but they do not harm the child. Nevertheless, inasmuch as the choices are sub-optimal, they are not what is best. So, if parents choose what the doctors judge is not optimal, why should their choice be acted upon?

Lynn Gillam as the author of this 'ethical tool' for dealing with doctor-parent disagreement argues that it 'accords appropriate moral weight to parents as the decisionmakers for the child'. ${ }^{43}$ This provokes the question, what is this 'appropriate moral weight', and what is its normative basis? Gillam does not make explicit why such a weighting is appropriate. It cannot be that opting for what is the parents' choice of treatment is the route of least resistance, and chosen inasmuch as the avoidance of disagreement, so long as the child is not harmed, has benefits or at least forestalls certain costs. Disagreement is indeed problematic, and it can lead to conflict, litigation and unresolved animosities. Yet, what is at stake is the future of a child. Moreover, requiring of doctors that they do what they do not think is best for the child has its own evident burdens, namely requiring them to do something other than what they are professionally obligated to do, namely do the best they can for their patient.

Parents are also not being asked to discharge a parental duty of care that is defined as maximising the child's interests. A best interests standard for all forms of parental care is open to familiar damaging criticisms, not least its over-demanding nature. As we have already argued, the presumption is that parents vary in their standards of care.

Moreover, the choice of the best medical care does not as such normally impose unreasonable costs on a parent. It is time limited and domain specific. It may well be that what the doctors commend as best for the child has costs for the parents who must subsequently care for the child. Preserving or prolonging a child's life may, for instance, be at the expense of significant disabilities that require an enormous devotion of time and resources to the life-long care of the child. In such a case it is appropriate to take account in making a decision not just of what is in the child's interests, but what is in the parents' interests. However, it does not change the appraisal of what is best for the child and, as such, the subject of the disagreement between parents and doctors.

A determination that what is objectively best for the child is not what his or her parents wish for is not equivalent to a loss of the right to parent. Parents are not thereby losing their general right to make choices for the child. It is only their choice in respect of medical care that might be overruled. It is thus not denied that the parents are, and will likely remain, the decision-makers for the child. The significance of that is not denied. After all, it is they - and not some other third party - who make up one side of the disagreement.

It is worth adding the following from, as it were, the other side. That parents have the right to make choices in the everyday life of their children and, in doing so, can legitimately exclude others from making these choices, does not give the choices of parents a special weight outside these normal quotidian contexts.

42 Lynn Gillam, 'The Zone of Parental Discretion: An Ethical Tool for Dealing with Disagreement between Parents and Doctors about Medical Treatment for a Child' (2006) 11(1) Clinical Ethics 1-8.

43 Ibid 2. 
What then remains of the 'appropriate moral weight' that the parents' views should have in cases of medical decision-making? It is important to distinguish between the weight that might be accorded to parents' choices just because and for no other reason than that they are the child's parents and the weight that might be accorded to parents' choices for some other reason that is in some way related to their status as the child's parents.

Here are some important instances of this latter kind of reason. The first is essentially epistemic and concerns who it is that is best placed to judge what is in a child's interests. A parent may plausibly claim that she knows better what is best for her child because she is a parent. She stands in a superior position to that of the doctor to gauge how the child feels or what the child wants. A parent is epistemically better placed than doctors to judge what is in her child's interests.

Yet, the crucial normative work in this claim is done by the interests of the child and not by the parental relation. This relation serves to explain a position of privileged knowledge and not as such to ground a moral entitlement to choose for the child. Thus, the assertion 'I am her parent and should choose' needs to be expanded to the following statement: 'As her parent I know her better than others, and given that it is whatever is best for her that should determine what is chosen I, as her parent, am better placed to judge what, all things considered, will be best for her.' Put in another and more concise way, there are two normative principles in play. The first is that the best should be done for a child. The second is that whosoever is best placed to judge what is best for the child should choose what is done. Conjoined with the further premise that the parent is so best placed, it follows that the parent should choose.

This is a valid argument, but everything turns on the epistemic premise. Parents, it is claimed, know their children better than anyone else. Why? Perhaps it is that they are close in every sense to their charges. Loving parents are moved to do what is best for their child. There is no better defender of this motivational claim than the seventeenth-century English philosopher, John Locke. He maintained that God:

... has in all the parts of creation taken a peculiar care to propagate and continue the several species of creatures, and makes the individuals act so strongly to this end, that they sometimes neglect their own private good for it, and seem to forget that general rule, which nature teaches all things, of self-preservation; and the preservation of their young, as the strongest principle in them, over-rules the constitution of their particular natures. ${ }^{44}$

This is a powerful claim. However, there are good reasons not to give this fact too much weight in the case of medical decision-making. Being motivated to do what is best for someone does not make one the best or even a better judge of what is in fact best. Love can indeed be blind. Even as a general rule, the claim that parents are better placed than others to judge what is best for the child is a defeasible one. The best medical decision may not rely on knowledge about a child's welfare that a parent alone has access to or is better placed to know. Doctors may - and indeed if they are conscientious should - take account of all relevant information, including that which can be best or only provided by parents.

Finally, a claim about superior epistemic access must always be carefully distinguished from other claims a parent might make on behalf of the child. A parent's claim that the child should continue to receive life-prolonging treatment may not express a view about what is best for the child, but rather what a parent wishes for. Such wishes may not simply

44 John Locke, Two Treatises of Government, critical edition with an introduction and apparatus criticus by Peter Laslett (Cambridge University Press 1963 [1698]) I.vi.\$56. 
be an expression of what the parent sees as in her interests and thus be open to the charge of a failure to disengage parental from a child's interests. The wishes in question may be the expression of a general view about, for instance, the value of life as such rather than of the value of this life. Whether it is important to this child to carry on living is distinct from the question of whether it matters to keep anyone alive.

However, it is important to acknowledge the interests of any parent. Indeed, Wilkinson and Nair give this as one reason to favour the harm principle over the best interests principle when deciding between parents and doctors. They think that if there is little to choose between doctor and parent in respect of what is best for the child then we should favour the parents' view so long as this is not harmful to the child. Indeed, the doctors' choice may be better for the child. Yet, 'where the benefit to child [sic] is statistically unlikely or small in magnitude it is reasonable to give parents' interests (or rights) some weight'. ${ }^{45}$ The suggestion is that the weight of parental interests might suffice to outweigh the putatively negligible or minor superior weight of the doctors' choice over the parents.

Now, how might the parents' interests count? There must be what Lainie Friedman Ross terms 'intra-familial trade-offs'. ${ }^{46}$ One cannot simply demand what is best for a child by giving no weight to the interests of other family members, including, but not exclusively, those of the parents. Thus, for instance and as acknowledged earlier, a medical decision for the child may have burdensome consequences for the parents. These must be factored into any overall decision as to what is best, and not just what is best for the child.

But acknowledging that a parent's interests in the outcome of any decision should be counted is not the same thing as giving an 'appropriate moral weight' to a parent's choices. For what a parent might choose for her child is thought to have a weight whatever the consequences for the parent herself. Moreover, those consequences enter into an allthings-considered judgment of what is best for the child. It is not that her interest in any outcome shows the parent to be the better chooser of what is best for the child or to have a greater moral claim to make the relevant choice. Rather, it supplies one significant consideration that should enter into in any full and nuanced judgment of what is the best choice for the child.

\section{Value pluralism and moral dilemmas}

Wilkinson and Nair argue that doctors and parents may disagree because of 'value uncertainty': that is, the relevant parties may appeal to distinct values in defence of their respective views about what is best for the child. They conclude: 'Where there are a range of different reasonable views about whether or not a particular treatment is in a child's best interests, it is unfair to impose one set of values on all parents. ${ }^{47}$ They do so in the context of a defence of the harm principle as that which should order deliberations about any choice of treatment.

The first thing then to say is that, presumably, they view that principle as not beset by the problem of value uncertainty. Doctors and parents can reach normative agreement on what counts as harm, even if they might disagree as to whether, as a matter of empirical fact, something is harmful. The 'uncertainty' in question concerns what is best for the child.

45 Wilkinson and Nair (n 37) 117.

46 Lainie Friedman Ross, Children, Families and Healthcare Decision-making (Clarendon Press 1998) 44.

47 Wilkinson and Nair (n 37) 117. 
Second, some disagreements between doctors and patients may not be about values (say, about the quality of a life), but rather be about factual matters (whether this treatment will work, for instance). And if it is the latter it is unclear why medical expertise should not be decisive.

Third, an appeal to the special knowledge a parent has of his or her child is not, as might be implied, relevant in this context. ${ }^{48}$ Such privileged knowledge as they have need not be of a sort that disposes to a better medical understanding of their child's condition. Nor, crucially, need it be one that shows their value claims to be more likely to be true.

Fourth, if, as argued here, we must adjudicate the disagreement by reference to best interests, then we should aim to make an objective determination of what is best. This may be difficult to do. But those who insist that an interpretation of what is meant by 'best interests' is impossibly arbitrary ${ }^{49}$ need to show why such a problem does not afflict the concept of 'harm'. It also needs to be shown why courts should not, as they do in many analogous situations, attempt to spell out how a critical standard should be construed and applied.

Perhaps the 'uncertainty' in question is meta-ethical, there being an irreducible plurality of values in play and no possible means of ordering these values or weighting them by means of some single foundational value.

This is, of course, possible. But it is also a substantive and controversial philosophical claim. There is a great difference between the claim, consistent with a denial that values are plural or that they cannot be rank ordered, that people reasonably disagree on moral matters, and the claim that such moral disagreement may reflect an underlying plurality of incommensurable values. It needs to be shown why the courts should not proceed on the presumption that they can make an objective determination of what is best for the child. Simply invoking the fact of reasonable disagreement does not suffice to show it.

The final thing to say is this. Even if there is an irresolvable disagreement of values between doctors and parents - irresolvable because the respective values cannot be measured against one another - it is far from clear why we should decide in favour of the parents. It is said that so deciding would be 'unfair' inasmuch as it would mean imposing one set of values - presumably those of the doctors - on the parents. Yet, why would it not be unfair to impose the parents' values on the doctors? After all they, as doctors, have a professional duty to do what they see as best for their patients, and they could not discharge that duty as they understand it if they must do what they do not believe to be the best for their patient.

Another way of expressing this point is by saying that each party to the disagreement has an interest in seeing their view prevail. The parents have an interest as the parents of this child; the doctors have an interest in doing what they view as their professional duty, indeed what they understand as their clearly defined legal duty of care. We can surely reasonably disagree about whose is the greater interest. But, even if we could say which was the greater, it is far from evident that these interests should play any role in determining which view prevails. For what matters, and all that matters, is that the best is

48 Dominic Wilkinson and Julian Savulescu, Ethics, Conflict and Medical Treatment: From Disagreement to Dissensu (Elsevier 2019) 89-91.

49 Robert H Mnookin, 'Foster Care: In whose Best Interests?' in Onora O’Neill and William Ruddick (eds), Having Children: Philosophical and Legal Reflections on Parenthood (Oxford University Press 1979) 179-213; Jon Elster, Solomonic Judgments: Studies in the Limitations of Rationality (Cambridge University Press) Part III 'Solomonic Judgements: Against the Best Interests'. 
done for the child. That someone has an interest in seeing that what is done is what they wish to be done is beside the point.

More generally, there are fair and unfair ways to resolve disagreements by settling upon one of two (or more) preferred outcomes. We might simply toss a coin. Whilst in one sense fair, that method seems arbitrary. Another is by means of a democratic vote. Yet, in the current context it is unclear who should be permitted to vote. Moreover, if the relevant suffrage is extended to the disputing parties, and we discount numbers on either side, we simply end up with a tie. A final method is that of an impartial, independent decision-maker. This is precisely what the court is.

There is a stronger version of the 'value uncertainty' claim that is defended by Raanan Gillon. This is that the disagreement between doctors and parents is a moral dilemma and that the parents' and doctors' views represent two horns of that dilemma. ${ }^{50}$ However, a moral dilemma is properly understood as a necessitated choice between two courses of action each of which has moral reasons in favour of it, such that the choice involves some kind of moral loss. The loss in question is the failure to do that which is not chosen and yet which we should have done. ${ }^{51}$

This is not a claim that the choice is between morally equivalent outcomes. That is extremely unlikely in the present context, but, if it was, nothing would be lost by choosing either one. The claim that we are dealing with a moral dilemma is stronger and other than the claim that the choices are morally incommensurable. The identification of a moral dilemma is such that, even if the choices can be compared and ranked, nevertheless, something is lost by choosing one outcome over the other.

However, it is not clear that the choice between the doctors' and parents' views of what is best for the child is a dilemma in this sense. We ought to do what is best for the child and the determination of one course of action as the best (whosoever's view that follows) does not leave a moral remainder. The other course of action is thereby characterised as inferior, but not one that still has moral reasons in its favour. We do have moral reason to do what is best for the child; we do not have a moral reason to do what is not best.

Perhaps it is thought that, nevertheless, something of value is lost, namely the choice of one of the two parties. Yet, it is strange to think that the choice as such has value. What is valuable is that which is chosen. Parents and doctors make choices of what is best for the child, and it is what is in fact best for the child that is valuable.

\section{Conclusion}

The slogan 'My child, my choice' is an evocative, emotive and understandably powerful battle cry and cri de coeur. It gives expression to an almost visceral sense of parental entitlement to determine what shall happen to one's child. Yet, at the end of the day, the disagreement between doctors and parents is about what is best for the child, not what is best for doctors or parents. It is about what is best, and not just about what does not harm the child. The best interests and harm principles have different domains of application, and it is important to distinguish them. Once we recognise that important distinction, we must proceed to adjudicate these disagreements in terms of what is best for the child.

50 Raanan Gillon, 'Why Charlie Gard's Parents should have been the Decision-makers about their Son's Best Interests' (2018) Journal of Medical Ethics 104.

51 Terrence McConnell, 'Moral Dilemmas' in Zalta (ed) (n 22) <https://plato.stanford.edu/archives/ sum2018/entries/moral-dilemmas>. 
Some think that favouring the views of the parent gives these an 'appropriate moral weight'. Yet, it has been argued here that there are no good reasons - grounded in the claim that parents know best, in the interests of the parents, in consistency with the use of the principles elsewhere, or in value uncertainty - to grant the views of parents a special and trumping moral weight over the views of doctors. We should continue objectively to determine what is best for the child, and do so by making use of an independent adjudicator. The courts fulfil such a role even if it is to be regretted that disagreements between doctors and patients must, as was so with the cases cited at the outset, be resolved through legal means. 
